\title{
STORM SURGE IN SETO INLAND SEA WITH CONSIDERATION OF THE IMPACTS OF WAVE BREAKING ON SURFACE CURRENTS
}

\author{
Han Soo Lee ${ }^{1}$, Takao Yamashita ${ }^{1}$, Tomoaki Komaguchi ${ }^{2}$, and Toyoaki Mishima ${ }^{3}$
}

\begin{abstract}
Storm surge and storm wave simulations in Seto Inland Sea (SIS) in Japan were conducted for Typhoon Yancy (9313) and Chaba (0416) using an atmosphere (MM5)-wave (SWAN)-ocean (POM) modeling system. In the coupled modeling system, a new method for wave-current interaction in terms of momentum transfer due to whitecapping in deep water and depth-induced wave breaking in shallow water was considered. The calculated meteorological and wave fields show good agreement with the observations in SIS and its vicinities. The storm surge results also exhibit good accordance with the observations in SIS. To resolve a number of islands in SIS, we also performed numerical experiments with different grid resolutions and obtained improved results from higher resolutions in wave and ocean circulation fields.
\end{abstract}

Keywords: Seto Inland Sea; storm surge; atmosphere-wave-ocean coupled model; air-sea interaction; whitecapping; depth-induced wave breaking

\section{INTRODUCTION}

Storm surge due to tropical cyclones (TCs) varies from place to place depending on the geographical features of the place we are interested in such as the effect of surrounding topography on meteorological fields, geographical shape of the bay or harbor, underwater bathymetry, tide, and interaction with other water bodies including rivers and open seas and oceans. In the storm surge modeling it is difficult to consider all of these effects such that we have to compromise some of them for simplifying a problem, more efficient modeling and engineering purpose. Typhoons is annual events in the western North Pacific (WNP) and Japan in WNP, in particular, is very vulnerable to typhooninduced natural hazards and disasters including the storm surges. As an islands country, Japan has many bays and harbors along the coasts and the places along the coasts facing to the Pacific have experienced a number of storm surges. Here we categorized the Japanese coasts into four types with a representative place according to the abovementioned geographical features (Lee et al. 2009) : 1) the Ariake Sea - this is a semi-enclosed sea in the west of Kyushu Island with high tidal range in the northern part. The wind set-up and storm waves during the high tide can bring a huge storm surge and related coastal damages (Lee et al. 2008). The key factor of storm surge modeling in these conditions is how to consider the interaction between the waves and tidal currents as well as the wind set-up. 2) Ise, Osaka, and Tokyo Bays - they are the most important three bays with the top three megacities of Japan located at the northern tip of the bays. They have common features that the entrances of the bays are in the south and their geographical shapes of the bays are elongated in southwest to northeast direction, which is the same direction with the southwest to northeast movement of typhoons. Therefore, the wind set-up might be the key factor in storm surge modeling, which largely depends on the track and translation speed of typhoon together with its meteorological conditions. 3) Tosa Bay - this is a small bay in the south of Shikoku Island facing directly to the Pacific Ocean. Due to the steep gradient of the bathymetry off the Tosa Bay, the wave set-up due to the depth-induced wave breaking is the critical factor in storm surge and its modeling, which needs a high spatial resolution to consider explicitly the wave set-up due to depth-induced wave breaking or coupling with a spectral wave model such as SWAN. 4) Seto Inland Sea (SIS) - this is the inland sea in the west of Japan surrounded by the Honshu in the north and east, Kyushu in the west, and Shikoku in the south. SIS is connected to the Pacific Ocean through two channels, Bungo in the west and Key in the east, and has a number of small islands. Therefore, the meteorological fields considering the orographic effects of surrounding mountainous areas and oceanographic fields considering a number of islands and the influence of the Pacific are important in storm surge and its modeling in SIS (Fig. 1). This classification in storm surge and its modeling based on the geographical features can be applicable not only in Japan but also in any other places unless they are vulnerable to TCs.

\footnotetext{
${ }^{1}$ Graduate School for International Development and Cooperation, Hiroshima University, 1-5-1 Kagamiyama, Higashi-Hiroshima 739-8529, Japan

2 Blue Wave Institute of Technology Co., Ltd, Tokyo, Japan

${ }^{3}$ Blue Wave Institute of Technology Co., Ltd, Higashi-Hiroshima, Japan
} 
In all types of storm surges above, a role of storm waves that override the tide and wind set-up should not be ignored in terms of energy (momentum) conservation even though they are considered in wave set-up due to radiation stress (Longuet-Higgins and Stewart 1964) in some cases. The interaction between air and sea including the role of waves is one of the most complicated problems that cannot be described in an exact and direct mathematical form due to interplay of several multiple-scale stochastic phenomena (Kitaigorodskii and Lumley 1983). Numerous researches in theoretical, experimental, and numerical approaches on air-sea interaction have been performed in terms of exchanging heat, momentum and water through the air-sea interface. On the long term, the convergence and divergence of oceanic heat transport provide source and sinks of heat for the atmosphere and partly responsible for the mean climate of the Earth. In large and long-term scale air-sea interactions, the understanding on how much the atmosphere and ocean influence each other is the key subject. On the other hand, the airsea interaction process in small and short-term scale occurs quickly due to a turbulent nature of mechanical motions at sea surface layer. Waves at air-sea interface are a medium for momentum transfer from wind to those mechanical motions at sea surface layer.

Understanding on these air-sea interaction processes and numerical modeling of such interactions are very important not only for storm surges but also for improving of wave and current prediction, calculation of heat and water exchange, and turbulent mixing, material transport, event bed formation, and many other applications. Recent researches on air-sea interaction using a coupled atmosphereocean model or a coupled wind-wave-current model consider it through a heat and water mass exchange, and a momentum transfer between air and sea. In most of numerical studies on the air-sea interaction (Edson et al. 2007; Fabrice Ardhuin et al. 2005; James Edson et al. 1999), the momentum transfer from wind waves to surface current is only considered in deep water through wave energy dissipation by whitecapping. However, the wave energy dissipation due to whitecapping contains the largest uncertainty among the source and sink terms for wave generation and decay (Cavaleri et al. 2007), and under certain conditions the energy dissipation due to whitecapping is overestimated in low frequency waves (Rogers et al. 2003). Lee and Yamashita (2009) showed an improved method to take into account the momentum transfer between waves and currents in the air-sea interaction in storm surge modeling.

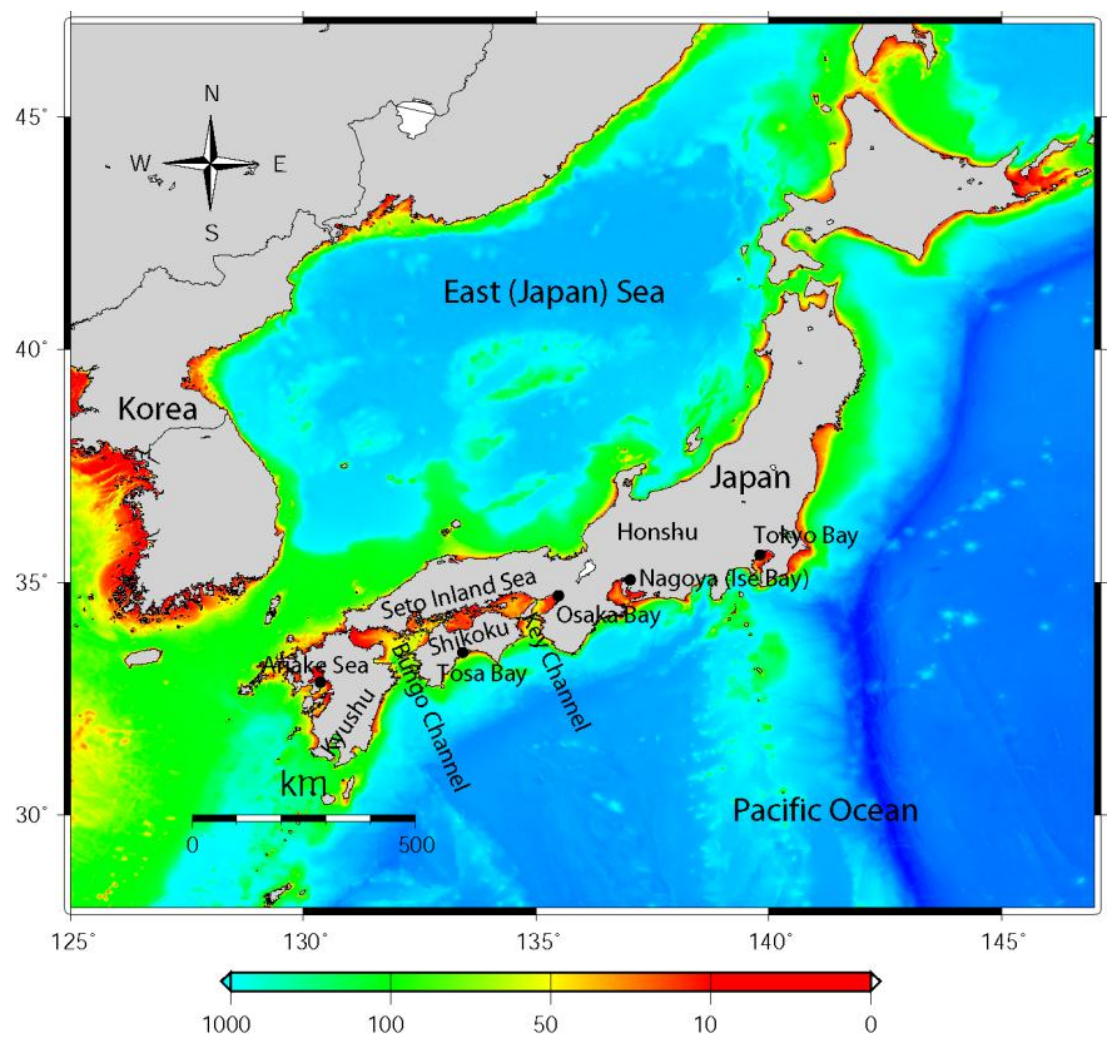

Figure 1. Japanese Islands showing the study area (Seto Inland Sea) with other bays and sea mentioned and categorized into four types based on their geographical features in the text. 
In this study, we focus on the storm surge and its modeling in SIS with our atmosphere-wave-ocean modeling system (Kim et al. 2008) for Typhoons Yancy (9313) and Chaba (0416) which brought the highest storm surge and tidal levels during the past 37 years from 1971 to 2008 (Table 1) in SIS. In the following, the method of storm surge modeling including an atmosphere-wave-ocean modeling system, the air-sea interaction process in terms of momentum transfer in the modeling system and model set-ups for storm surge calculation is described in Section 2. The results of storm surge simulations for Typhoons Yancy and Chaba are presented in Section 3, which is followed by the summary and concluding remarks in Section 4.

\section{METHOD}

\section{Atmosphere-wave-ocean modeling system}

The atmosphere-wave-ocean modeling system consists of three public domain models, which are a non-hydrostatic mesoscale meteorological model, MM5 (Grell et al. 1995), for atmosphere, a thirdgeneration spectral wave model, SWAN (Booij et al. 2004), for wind waves and a sigma-coordinate primitive equation ocean model, POM (Mellor 2004), for ocean. For more details of each model, refer to the references. Three models are connected by own-developed flux coupler which transfers the physical parameters and controls the overall simulation time through a multiple common time step among the components models. Fig. 2 shows the modeling system with the exchanging physical parameters.

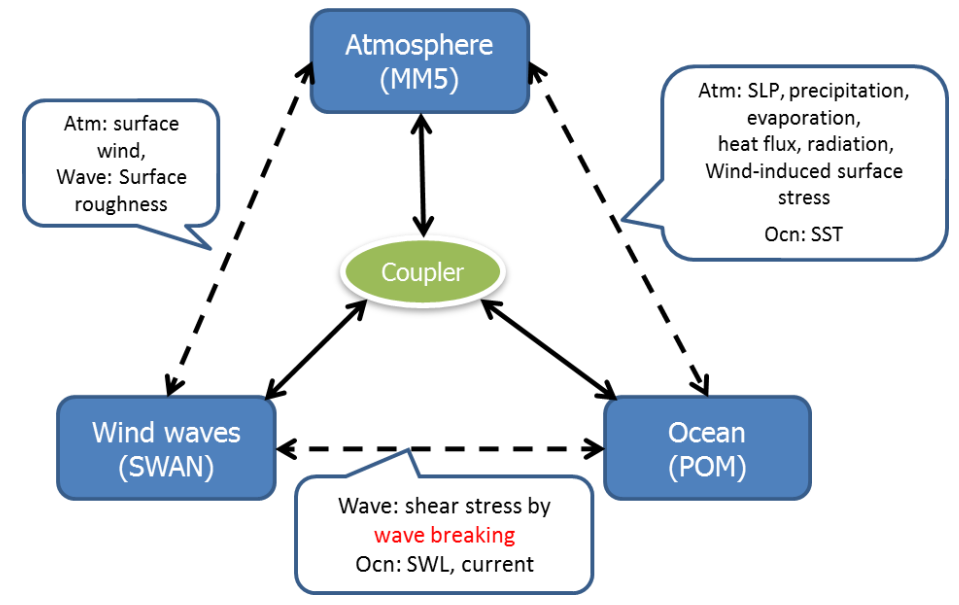

Figure 2. An atmosphere-wave-ocean modeling system used in this study.

\section{Air-sea interaction: Momentum transfer between wind waves and currents}

Even it is difficult to describe the waves and currents interaction in direct mathematical form, the description in some extent has been achieved due to spectral presentation of wind wave dynamics (Polnikov and Tkalich 2006).

Due to the wave instability and breaking, some part of dissipated wave energy is generating turbulence in sea surface layer in both deep and shallow water. These intensive small scale motions are important in many applications dealing with air bubbles entrainment, vertical mixing of admixtures, heat and gas exchange, and many others (Qiao et al. 2004; Tkalich and Chan 2002). Here we assume the all dissipated wave energy is used for turbulent production in sea surface layer and for generating or enhancing the large scale motions such as currents. Therefore, the rest of the dissipated wave energy by wave breaking is changed into momentum to generate or enhance currents. Wave breaking phenomena considered in this study is whitecapping dominant in deep water and depth-induced wave breaking dominant in shallow water. Whitecapping mainly depends on the wave steepness whereas wave breaking in shallow water depends on water depth. Thus, wind wave energy dissipation due to whitecapping in deep water affects the upper layer of water column while the transformed momentum from dissipated wave energy due to depth-induced wave breaking in shallow water may have influence on the state of the entire water column. 




Figure 3. The air-sea interaction process; momentum transfer between wind-wave-current considering the whitecapping and depth-induced wave breaking in deep and shallow water respectively

We introduce a new method to consider the role of depth-induced wave breaking in shallow water separately from the whitecapping in deep water. In addition, dissipation coefficients are also introduced to take into account the turbulence production in sea surface layer due to wave breaking both in deep and shallow water implicitly as well as the momentum transfer from waves to surface currents explicitly.

It is now possible to estimate the wave energy dissipation due to wave breaking quantitatively by using a spectral wind wave model, although the observations are difficult under strong storm condition. In a spectral wind wave model, SWAN, the wind wave energy spectrum grows or decays corresponding to the energy balance in source and sink terms. Sink terms due to whitecapping $\left(S_{d s(w)}\right)$ in deep water and depth-induced wave breaking $\left(S_{d s(d e p)}\right)$ in shallow water are also estimated from the spectral action balance equation. The action balance equation in SWAN can be written in spherical coordinate for the large scale applications as;

$$
\frac{\partial N}{\partial t}+\frac{1}{\cos \phi} \frac{\partial}{\partial \phi} \dot{\phi} N \cos \theta+\frac{\partial}{\partial \lambda} \dot{\lambda} N+\frac{\partial}{\partial k} \dot{k} N+\frac{\partial}{\partial \theta} \dot{\theta}_{g} N=\frac{S}{\sigma}
$$

where $\lambda$ and are the longitude and latitude. The source and sink terms $(S)$ are given as;

$$
S=S_{i n}+S_{d s(w)}+S_{n l 4}+S_{b o t}+S_{d s(d e p)}+S_{n l 3}
$$

Among the source and sink terms, the energy input source term from wind to waves $\left(S_{\text {in }}\right)$, the whitecapping sink term $\left(S_{d s(w)}\right)$ and the nonlinear wave energy transfer due to quadruplet interaction $\left(S_{n l 4}\right)$ are estimated in deep water while the dissipation sink term due to bottom friction $\left(S_{b o t}\right)$, the depthinduced wave breaking sink term $\left(S_{d s(d e p)}\right)$, and the nonlinear triad interaction $\left(S_{n l 3}\right)$ are calculated in the shallow water.

Then the shear stresses to surface currents induced by whitecapping and depth-induced wave breaking in deep and shallow water respectively are given as;

$$
\begin{gathered}
\tau_{\text {dis(whitecapping })}=K_{s(w)} \rho g \iint \frac{S_{d s(w)}(\sigma, \theta)}{C} d \sigma d \theta \\
\tau_{\text {dis(depth-induced })}=K_{s(d e p)} \rho g \iint \frac{S_{d s(d e p)}(\sigma, \theta)}{C} d \sigma d \theta
\end{gathered}
$$


where $\rho, g, \sigma$, and $\theta$ are the density of water, the gravitational acceleration, the frequency, and the direction. The $K_{s(w)}$ and $K_{s(d e p)}$ are dissipation coefficients for whitecapping and depth-induced wave breaking respectively, which represent on how much of dissipated wave energy is used for generating or enhancing the currents. The dissipation coefficient in shallow water can be determined by concept of radiation stress based on the idea that the principal force for currents under breaking waves is represented by the reduction in radiation stress, which in turn may be related to the dissipation of wave energy (Deigaard 1993; Nairn et al. 1990). Therefore, we introduce the dissipation coefficient in shallow water as follows;

$$
\begin{gathered}
K_{s(\text { dep })}=\frac{\tau_{\text {dis }(\text { depth-induced })}}{F} \\
F=\sqrt{F_{x}^{2}+F_{y}^{2}}=\sqrt{\left(-\frac{\partial S_{x x}}{\partial x}-\frac{\partial S_{x y}}{\partial y}\right)^{2}+\left(-\frac{\partial S_{y x}}{\partial x}-\frac{\partial S_{y y}}{\partial y}\right)^{2}}
\end{gathered}
$$

where $F_{x}$ and $F_{y}$ are wave-driven stresses and $S_{X X}$ is the radiation stress. The dissipation coefficient due to whitecapping is inductively determined by comparing final storm surge level after determination of the dissipation coefficient due to depth-induced wave breaking in coupled modeling.

The waves and currents interaction through Eq. (3) to (6) were implemented in the atmospherewind waves-ocean modeling system. Figure 4 shows the synoptic diagram of the coupled model in terms of momentum transfer from wind to waves, from wind to currents, and from waves to currents considering the wave breaking in deep and shallow water.

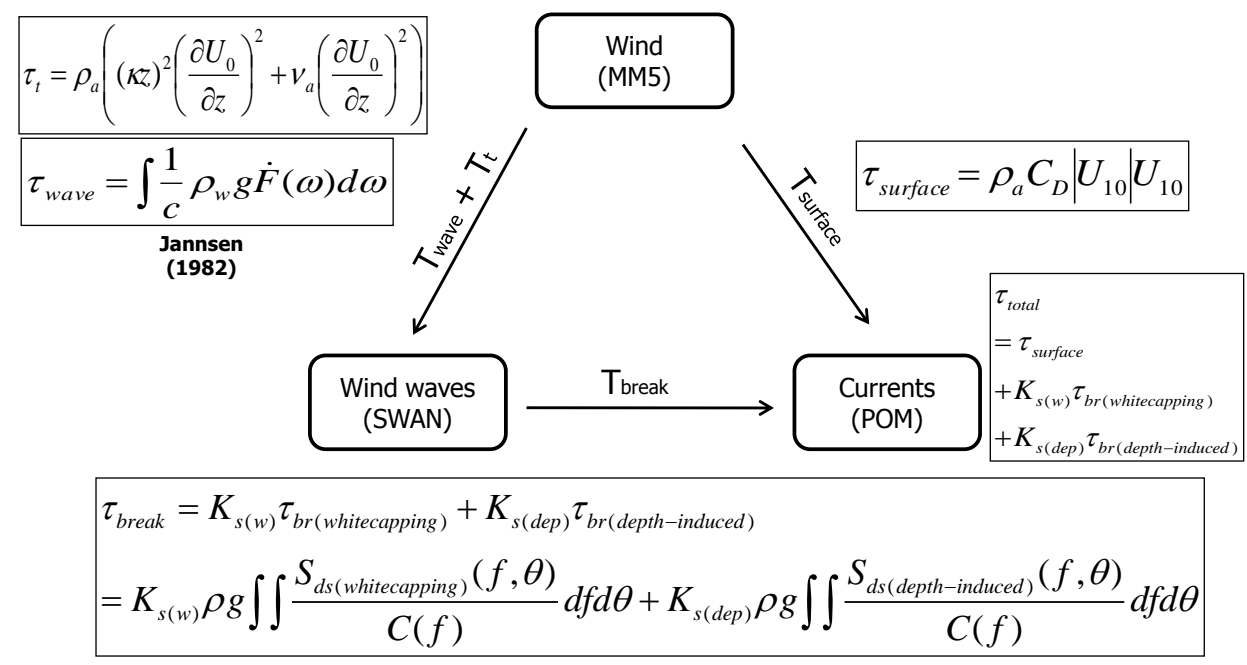

Figure 4. The atmosphere-wind waves-ocean coupled model showing the interaction process in terms of momentum transfer between wind-wave-current

\section{Model set-up for storm surge simulation in Seto Inland Sea}

Table 1 shows the past 20 typhoons from 1971 to 2008 that caused a storm surge over $50 \mathrm{~cm}$ in any of tidal stations in SIS or a tidal level over $200 \mathrm{~cm}$ if a storm surge level is unknown. Among them, we selected the Typhoons Yancy and Chaba for storm surge modeling, which recorded the highest storm surge and tidal levels.

For all simulations, the MM5 simulations were conducted for three domains with 27, 9, and $3 \mathrm{~km}$ grid intervals considering the domain 3 to cover the whole SIS with the surrounding mountainous areas and two channels to the Pacific Ocean. The background and initial data for Typhoon Yancy was taken every six hours from JRA-25 data (1.125deg horizontal resolution) of JMA (Onogi 2007) while for Typhoon Chaba from NCEP FNL Operational Model Global Tropospheric Analyses (1deg horizontal resolution) (http://dss.ucar.edu/datasets/ds083.2/). Four-dimensional Data Assimilation (FDDA) was also applied with the same data. The simulation periods are as follows; a) 29 August to 6 September 1993 for Typhoon Yancy, and b) 23 August to 31 August 2004 for Typhoon Chaba. 


\begin{tabular}{|c|c|c|c|}
\hline Typhoons & Periods & $\begin{array}{l}\text { Observed maximum water levels }(\mathrm{cm}) \\
\text { during the periods (station) }\end{array}$ & $\begin{array}{l}\text { Maximum storm surge } \\
\text { levels }(\mathrm{cm}) \text { during the } \\
\text { periods (station) }\end{array}$ \\
\hline T0613 & $09 / 16 \sim 09 / 18$ & 336(Uno) & \\
\hline T0514 & $09 / 03 \sim 09 / 08$ & 381(Takamatsu),376(Uno),568(Hiroshima) & \\
\hline T0410 & $07 / 30 \sim 08 / 02$ & 378(Takamatsu),552(Hiroshima) & \\
\hline T0416 & $08 / 28 \sim 08 / 31$ & 436(Takamatsu),428(Uno),572(Hiroshima) & \\
\hline T0418 & $09 / 06 \sim 09 / 08$ & 377(Uno),573(Hiroshima),329(Kobe) & \\
\hline T0421 & $09 / 29 \sim 09 / 30$ & 323(Sumoto) & \\
\hline T0310 & 08/07 08/09 & 356(Takamatsu) & \\
\hline T0111 & $08 / 20 \sim 08 / 21$ & 227(Hiroshima),151(Uno) & \\
\hline T9918 & $09 / 27 \sim 09 / 28$ & & \\
\hline T9719 & $09 / 13 \sim 09 / 17$ & 374(Takamatsu),192(Uno),241(Hiroshima) & $57($ Uno) \\
\hline T9612 & $08 / 13 \sim 08 / 15$ & 184(Takamatsu),186(Uno) & 94(Takamatsu),101(Uno) \\
\hline T9313 & $09 / 03 \sim 09 / 04$ & 119(Kobe) & 112(Kobe) \\
\hline T9210 & $08 / 08 \sim 08 / 09$ & 250(Himeji) & 70(Himeji) \\
\hline T9119 & $09 / 27 \sim 09 / 28$ & $\begin{array}{l}510 \text { (Matsuyama),370(Uno),216(Hiroshima } \\
\text { harbor) }\end{array}$ & $\begin{array}{l}\text { 99(Takamatsu),88(Hiroshi } \\
\text { ma harbor) }\end{array}$ \\
\hline T9014 & $08 / 21 \sim 08 / 22$ & $\begin{array}{l}\text { 325(Uno),203(Hiroshima } \\
\text { harbor),292(Sumoto) }\end{array}$ & $52($ Uno) \\
\hline T8013 & $09 / 10 \sim 09 / 11$ & 234(Hiroshima) & 96(Hiroshima) \\
\hline T7506 & $08 / 22 \sim 08 / 23$ & 173(Takamatsu) & 70(Takamatsu) \\
\hline T7416 & $08 / 31 \sim 09 / 02$ & 164(Takamatsu),293(Kobe) & 53(Takamatsu) \\
\hline T7209 & $07 / 23 \sim 07 / 24$ & 352(Takamatsu) & 60(Takamatsu) \\
\hline T7119 & $08 / 04 \sim 08 / 06$ & 199(Okayama) & 58(Okayama) \\
\hline
\end{tabular}

In SWAN simulations, the wind forcing for three domains for each case were taken from MM5 results considering the whitecapping and depth-induced wave breaking separately for interaction processes. In the wave modeling, underestimation of wave energy spectrum in low-frequency in SWAN was modified for the simulations following Rogers et al., (2003). The bathymetry data were from the 1min GEBCO data (IOC et al. 2003) for domain 1 and 2 and from J-EGG500 (JODC-Expert Grid data for Geographic - 500m) (http://www.jodc.go.jp/data_set/jodc/jegg_intro.html) for domain 3 which gives much details of bottom topography in the SIS. In addition, we conducted numerical experiments to ensure the current and flow regime through the narrow inner SIS channel by resolving the domain 3 with much smaller grid intervals of $3,1.5,0.75$, and $0.5 \mathrm{~km}$.

(a)

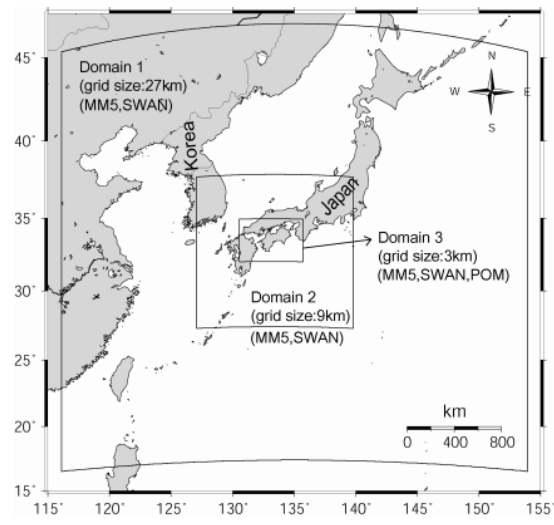

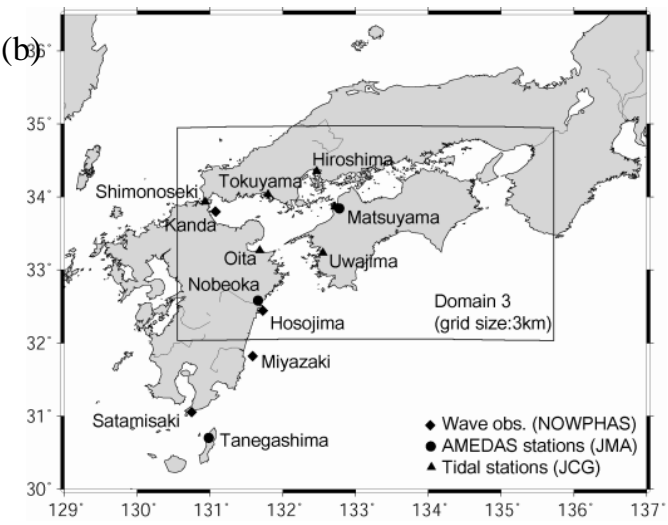

Figure 5. (a) The computational domain configuration and (b) the observation stations for tide, wave, and meteorological fields.

In storm surge simulations with POM in this study, only domain 3 in each case was used for same periods with atmosphere and wave modelings. The meteorological forcing (wind and pressure) and wave forcing (momentum flux due to whitecapping and depth-induced wave breaking) were considered for external forcings as well as the prescribed tidal forcing of 8 constituents (M2, S2, K1, O1, N2, K2, P1, and Q1) at lateral open ocean boundaries from the National Astronomical Observatory's ocean tide model (Matsumoto 2000). For all storm surge simulations, the barotropic ocean states were considered such that the influences of temperature and salinity profiles in the ocean were remained uniform. The 
bathymetry for domain 3 for POM simulations was also from J-EGG500. The numerical experiments with different horizontal grid resolutions were conducted in the storm surge simulation with POM as well.

\section{RESULT}

The calculated wind velocities while approaching to Japan and just before making landfall over Kyushu for Typhoons Yancy and Chaba are presented in Figure 6. Also the wind field comparisons at Nobeoka and Matsuyama AMeDAS stations from JMA for Typhoons Yancy and Chaba are shown in Figures 7 and 8, respectively. Overall, it shows good agreement between the calculated and observed values. At Matsuyama station for Typhoon Chaba the calculated wind speed shows slight overestimation before approaching to the station. One of the possible reasons to explain the overestimation is that the uncertainty of the radii for maximum winds of the typhoon produces the lower peak winds and larger radii in a horizontal vortex wind profile due to the coarse model resolution. The Figure 9 shows the spatial distribution of the maximum significant wave heights during the simulation periods from domain 1 for the two typhoons. Figures 10 and 11 show the distribution of the maximum significant wave heights from domain 3 of which the grid interval are different with $3,1.5,0.75$, and 0.5 $\mathrm{km}$ for Typhoons Yancy and Chaba, respectively. The complex coastline and a number of small islands are better resolved in 750 and $500 \mathrm{~m}$ grid intervals compared to those from 3 and $1.5 \mathrm{~km}$. The wave height distributions in $750 \mathrm{~m}$ resolution are improved very well compared to the coarser grid results.

Figure 12 shows the comparison of significant wave heights and mean periods between the calculated and observed at Kanda, Hosojima, and Miyazaki stations. At Kanda station located at the inner north part of the SIS near Shimonoseki shows good agreement between them and the grid interval induced about the $30 \mathrm{~cm}$ difference in significant wave height at peak. In the mean period, there is about $1 \mathrm{sec}$ difference calculated from the different grid resolutions.


Figure 6. Calculated wind velocities by MM5 at $10 \mathrm{~m}$ height at given times for Typhoons Yancy (upper panel) and Chaba (lower panel) 

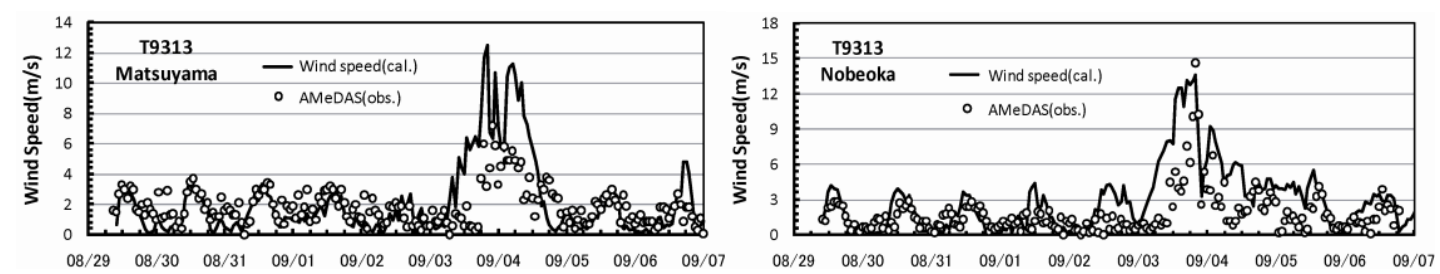

Figure 7. Comparison between the calculated and observed wind speeds at Matsuyama and Nobeoka stations (JMA) for Typhoon Yancy
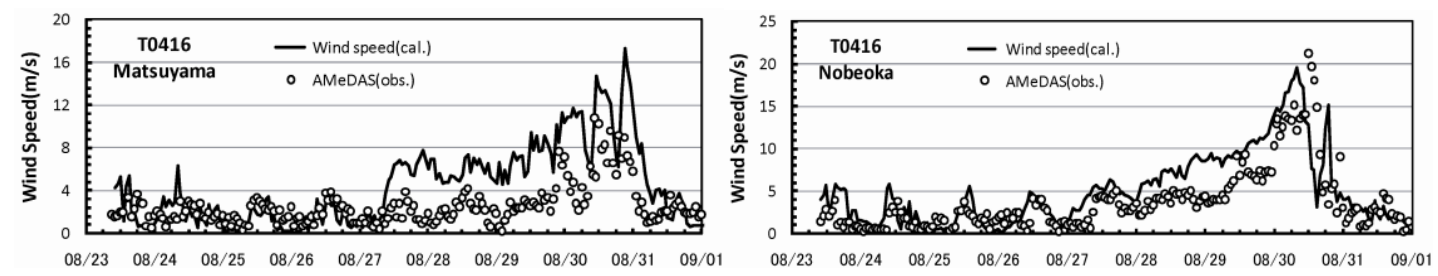

Figure 8. As in Figure 7, but for Typhoon Chaba

The results from $1.5 \mathrm{~km}$ grid resolution produced better results compared to those of $3 \mathrm{~km}$ one. Among the results of $1.5 \mathrm{~km}, 750$ and $500 \mathrm{~m}$ grid resolutions, not much difference in the results is observed. At Hosojima located at southeast of Bungo Channel, the significant wave heights until the landfall show slight underestimation. In the mean period, 2 to $3 \mathrm{sec}$ differences are observed in the comparison among the results from the different grid resolutions. In particular, the result from the 500 $\mathrm{m}$ resolution shows lesser mean period to the others. At Miyazaki station located far south to the Pacific, the significant wave heights show good consistency with the observation except the very peak and the mean periods also show good accordance with the observation even though the observation at peak is not available.

Figure 13 shows the comparison of tidal level between the calculated and observed values at Hiroshima, Matsuyama, Oita, Tokuyama, and Uwajima from top to bottom for Typhoon Yancy. The left and right columns of the figure show the results from the 1.5 and $3 \mathrm{~km}$ grid resolution experiments. At Uwajima and Oita, the calculated values depict good agreement with the observed tidal levels. However, the difference between the calculated and observed gets larger as moving to the inner part of the SIS. The difference at Hiroshima station shows about $30 \mathrm{~cm}$. Also the phase lag can be observed from the comparison results at inner stations in SIS. The difference in the grid interval experiments shows that the results of calculated tidal levels from $1.5 \mathrm{~km}$ resolution show better agreement with the observations than those from $3 \mathrm{~km}$ resolution with lesser phase lag of tide. These indicate that the calculation of accurate water masses through the SIS is a key factor not only for the storm surge simulations but also for understanding oceanographic processes occurring in the SIS.


Figure 9. Spatial distribution of maximum significant wave height during the simulation periods in domain 1 for Typhoons Yancy (left) and Chaba (right) 

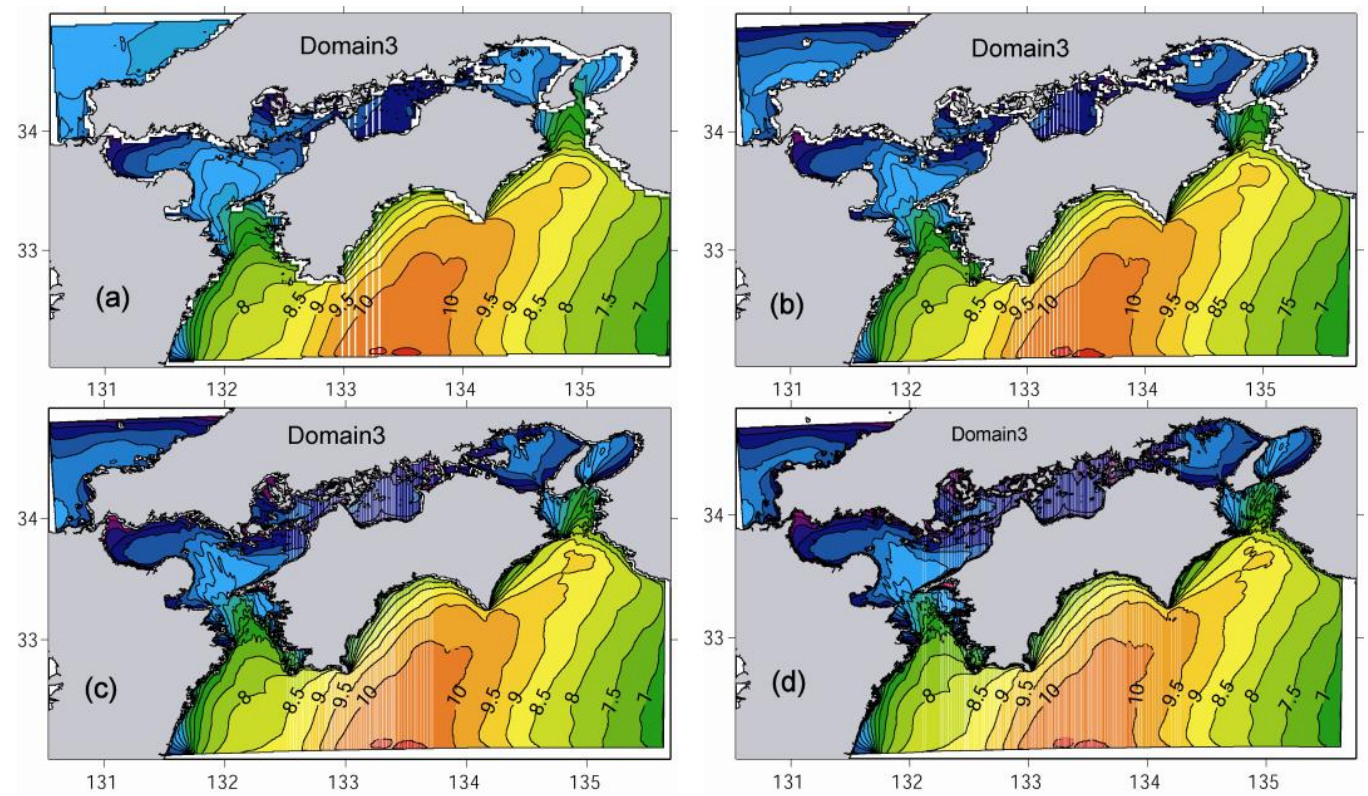

Figure 10. Spatial distribution of maximum significant wave height during the simulation period in domain 3 for Typhoon Yancy from different grid interval experiments: (a) $3 \mathrm{~km}$, (b) $1.5 \mathrm{~km}$, (c) $750 \mathrm{~m}$, and (d) $500 \mathrm{~m}$
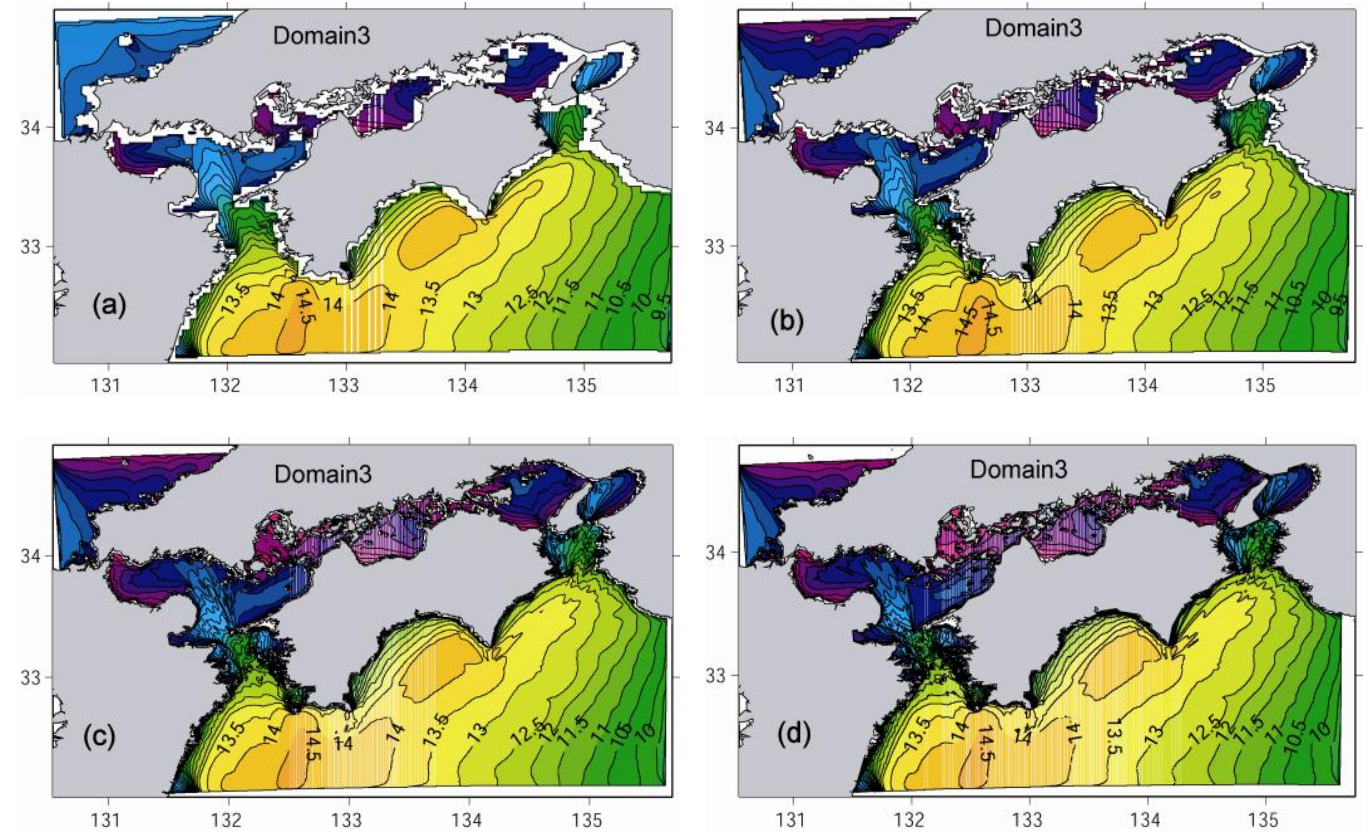

Figure 11. As in Figure 10, but for Typhoon Chaba

Figure 14 shows the calculated and observed tidal level comparisons as in Figure 13 but for Typhoon Chaba. The results depict same trends in tidal levels and tide phase lag indicating the importance of enough high resolution in ocean modeling. 

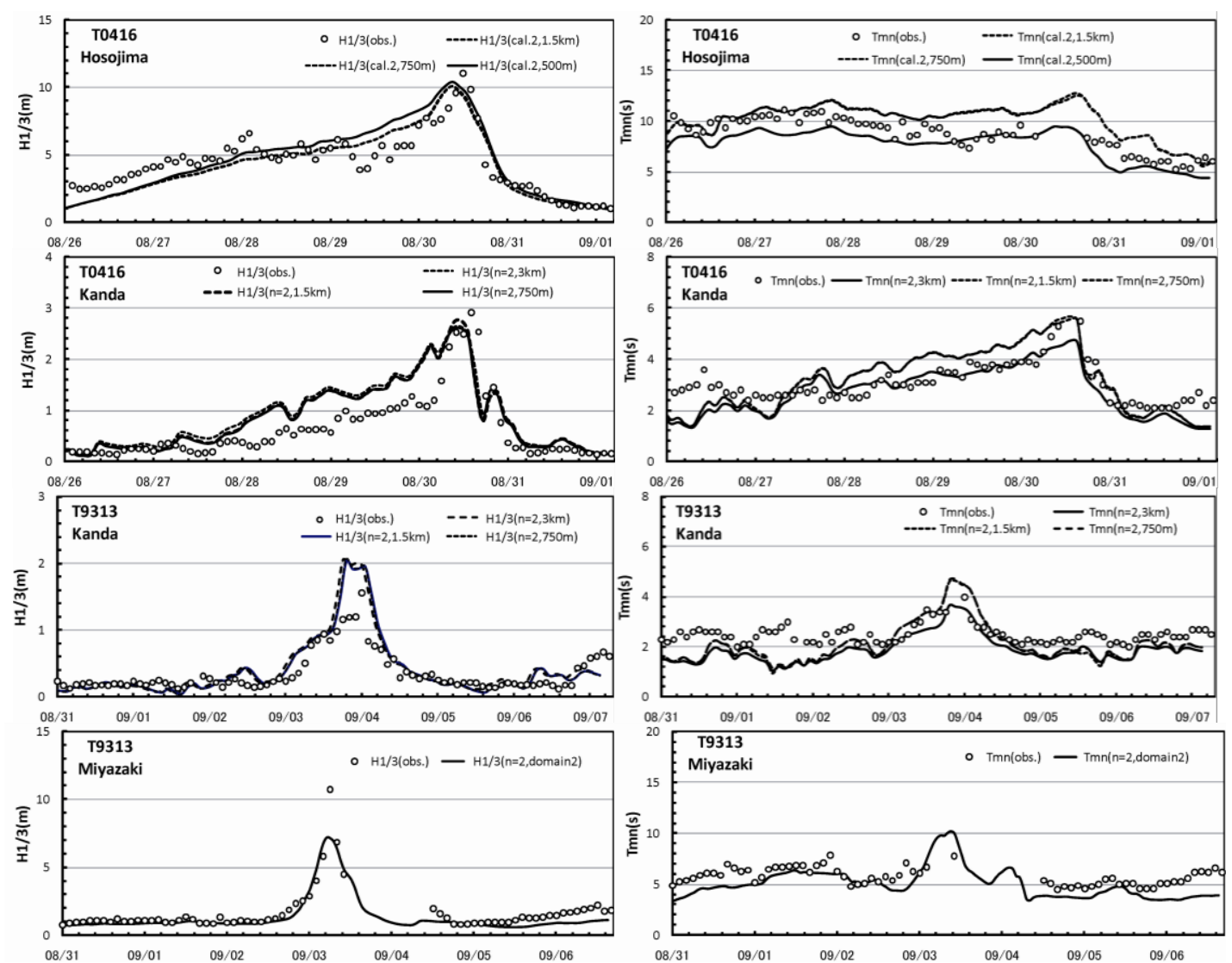

Figure 12. Comparison between the calculated (by SWAN) and observed wave significant heights and mean periods at Hosojima, Kanda, and Miyazaki stations (NOWPHAS from PARI) for Typhoons Yancy and Chaba. Note that the dashed lines indicate the results from the different grid interval experiments if the stations are located within the domain 3.
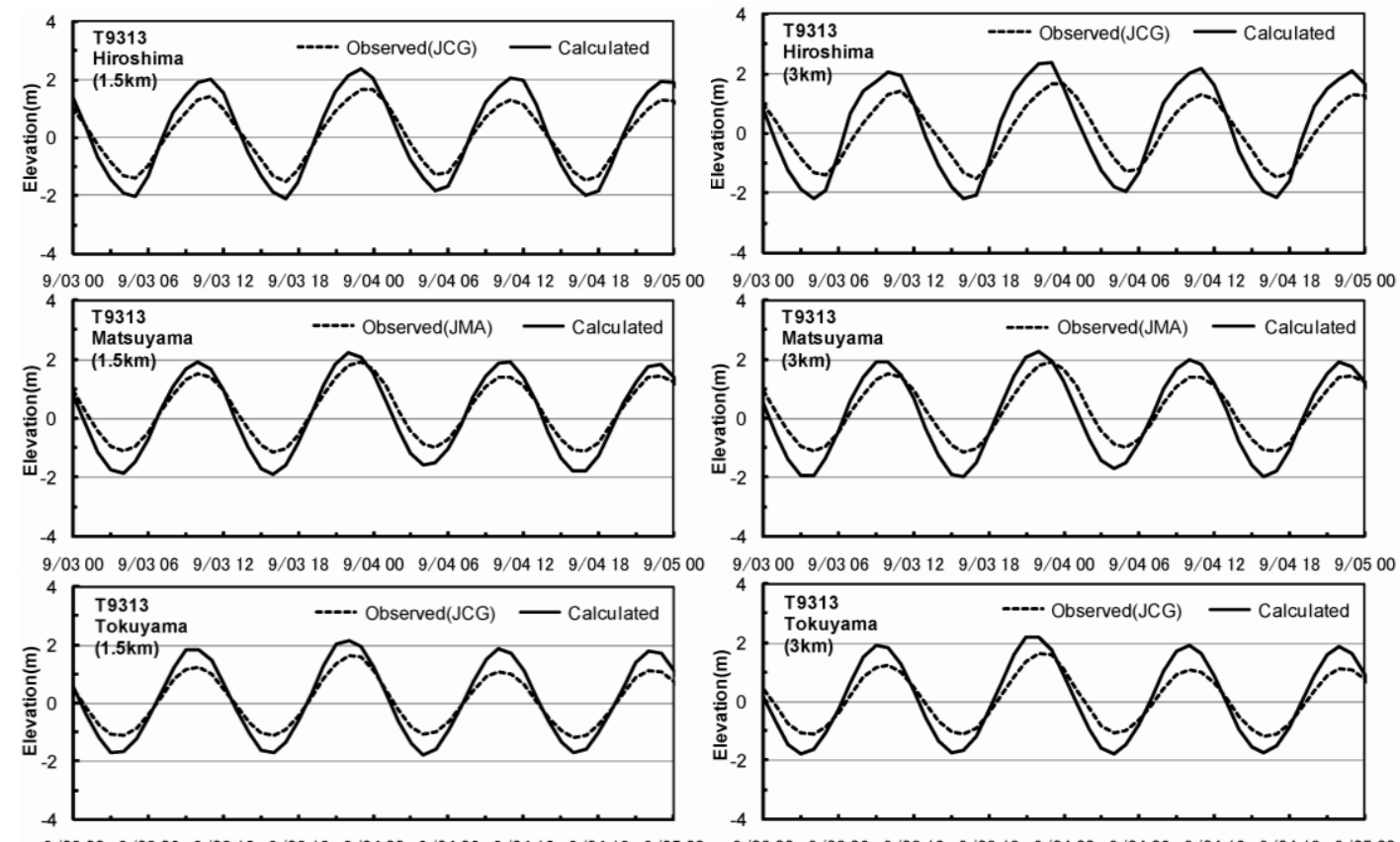

Figure 13. Continued. 



Figure 13. Comparison between the calculated (by POM) and observed tidal levels at Hiroshima, Matsuyama, Tokuyama, Oita, and Uwajima stations (JCG) for Typhoon Yancy. Note that the stations from Hiroshima (top) to Uwajima (bottom) are located at from the inner of SIS to the outer to the Pacific consecutively in space. The left column shows the results from the $1.5 \mathrm{~km}$ grid interval of domain 3 and the right ones from $3 \mathrm{~km}$ grid interval.
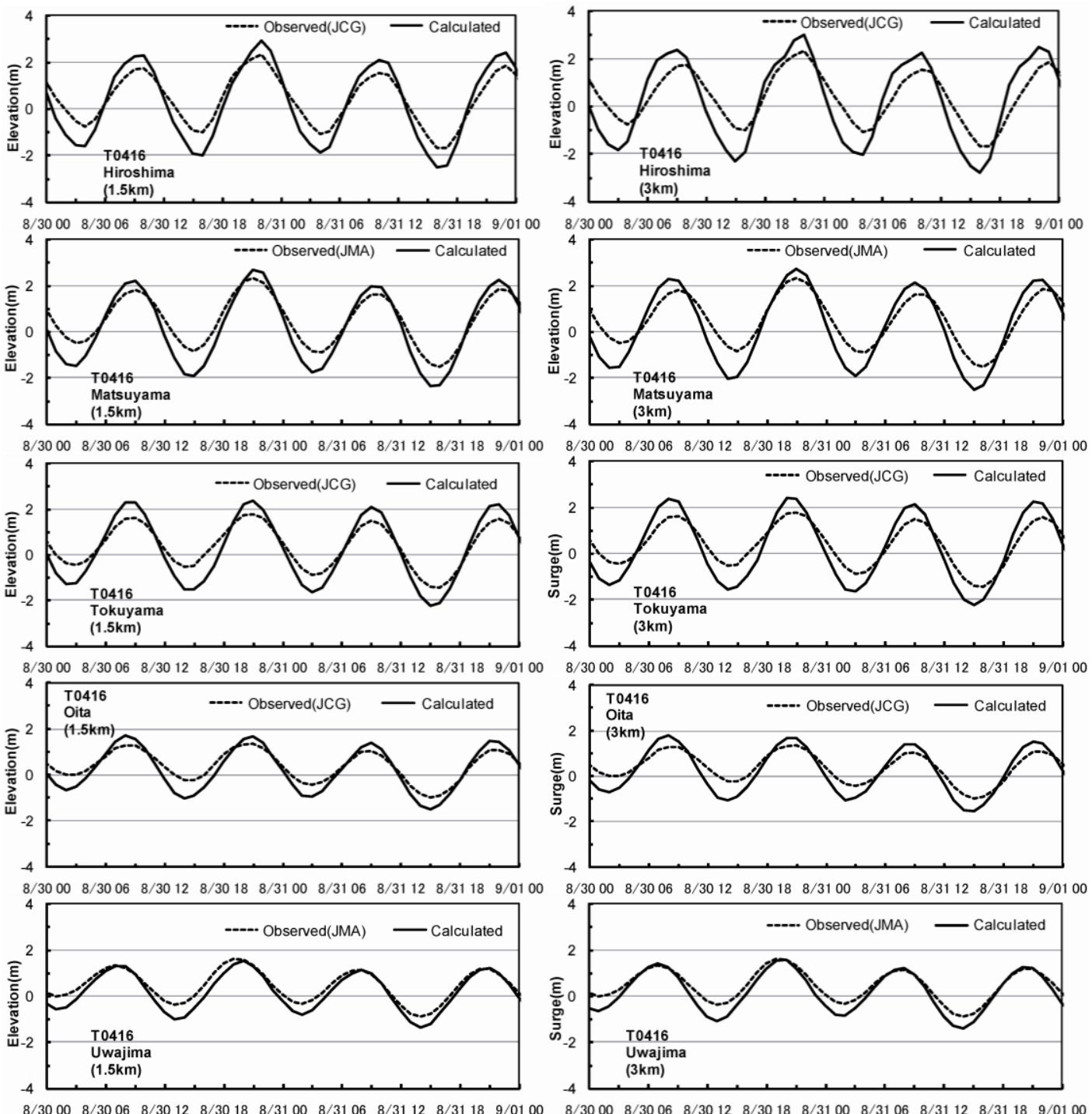

Figure 14. As in Figure 13, but for Typhoon Chaba 
Figures 15 and 16 shows the calculated storm surge levels at five difference stations in SIS for Typhoon Yancy and Chaba with 1.5 and $3 \mathrm{~km}$ grid intervals. The results from $3 \mathrm{~km}$ grid resolution show larger storm surge levels at inner part of SIS with lager oscillations. The difference of storm surge level induced from the grid resolution difference is larger in Typhoon Chaba that brought the highest tidal record since 1971 .

The impact of the momentum transfer from wind waves to currents due to whitecapping in deep water and depth-induced wave breaking in shallow water was considered in all of storm surge simulations in SIS with the wave energy dissipation coefficients, $K_{s(w)}$ and $K_{s(d e p)}$, set to one indicating a sort of ideal situation that the all dissipated wave energy transfer to surface currents. Since the calculated significant wave heights in the SIS were small (less than $3 \mathrm{~m}$ ) even in Typhoon Chaba, the impacts of wave-induced additional momentum were insignificant in the form of water levels. However, importance of the wave-current interaction through the momentum transfer due to wave breaking cannot be underestimated in the current fields in SIS and in other applications in other places.

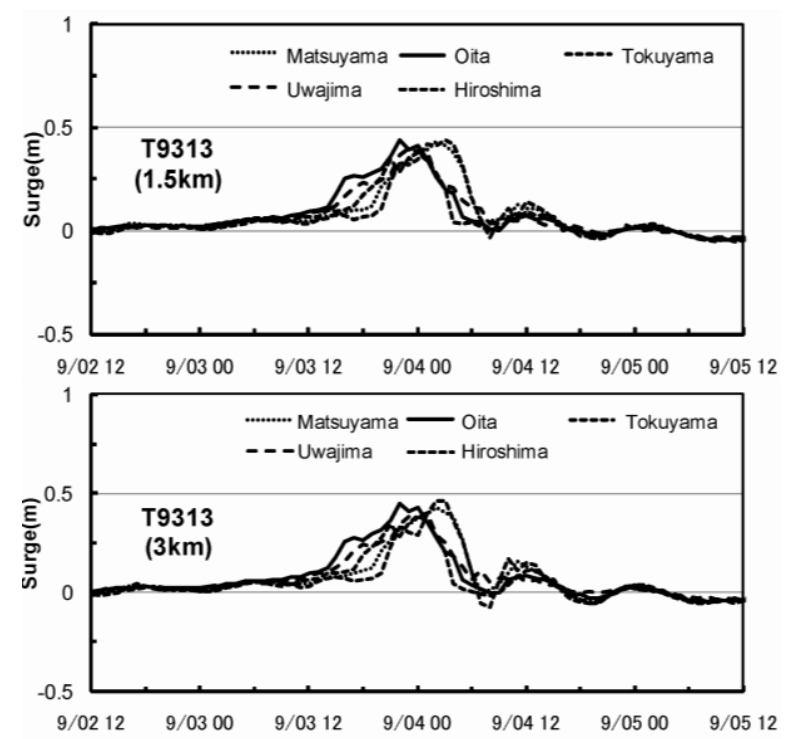

Figure 15. Calculated storm surge levels from the 1.5 and $3 \mathrm{~km}$ resolutions of domain 3 at Hiroshima, Matsuyama, Tokuyama, Oita, and Uwajima stations for Typhoon Yancy.

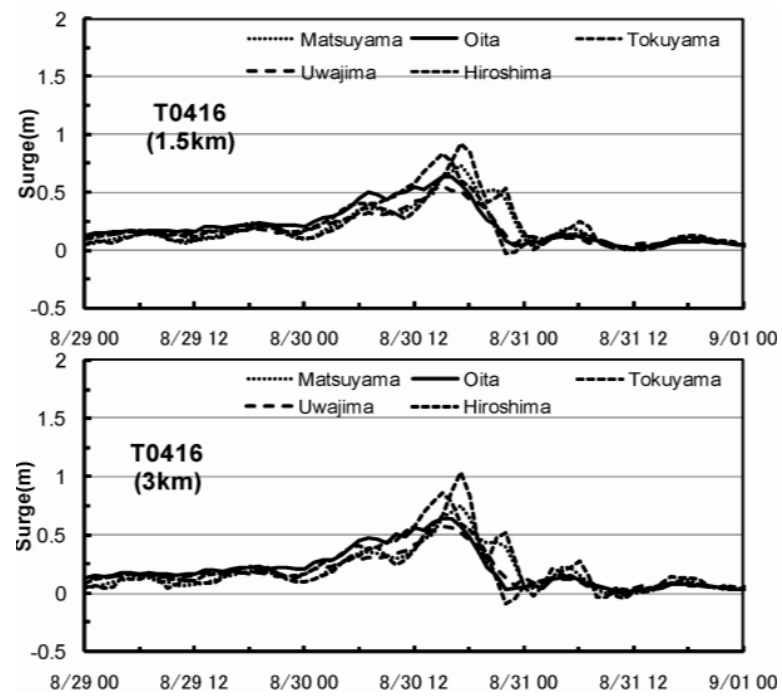

Figure 16. As in Figure 15, but for Typhoon Chaba 


\section{SUMMARY AND CONCLUDING REMARKS}

We have conducted storm surge simulations in the Seto Inland Sea, Japan, for Typhoons Yancy (9313) and Chaba (0416) using an atmosphere-wave-ocean modeling system. A concept of momentum transfer from waves to currents due to wave breaking (whitecapping in deep and depth-induced wave breaking in shallow water) was presented and implemented in the modeling system.

The results show that it is necessary to consider the orographic effects around the SIS in the meteorological field and a number of islands within the SIS in the oceanographic fields. The numerical experiments with various grid intervals reveal rather obviously that a simulation with an enough high resolution is essential in the SIS. The simulation results for meteorological fields, waves, and storm surge levels from our modeling system show overall good agreement with the observations.

\section{ACKNOWLEDGMENTS}

This research partly was supported by the Global Environmental Reader Education Programme at Graduate School for International Development and Cooperation in Hiroshima University.

\section{REFERENCES}

Booij, N., I. G. Haagsma, L. H. Holthuijsen, A. T. M. M. Kieftenburg, R. C. Ris, A. J. v. d. Westhuysen, and M. Zijlema. 2004. SWAN User Manual, SWAN Cycle III version 40.41, Delft University of Technology.

Cavaleri, L., J. H. G. M. Alves, F. Ardhuin, A. Babanin, M. Banner, K. Belibassakis, M. Benoit, M. Donelan, J. Groeneweg, T. H. C. Herbers, P. Hwang, P. A. E. M. Janssen, T. Janssen, I. V. Lavrenov, R. Magne, J. Monbaliu, M. Onorato, V. Polnikov, D. Resio, W. E. Rogers, A. Sheremet, J. McKee Smith, H. L. Tolman, G. van Vledder, J. Wolf, and I. Young. 2007. Wave modeling The state of the art, Progress In Oceanography, 75(4), 603-674.

Deigaard, R. 1993. A note on the three-dimensional shear stress distribution in a surf zone, Coastal Engineering, 20(1-2), 157-171.

Edson, J., T. Crawford, J. Crescenti, T. Farrar, N. Frew, G. Gerbi, C. Helmis, T. Hristov, D. Khelif, A. Jessup, H. Jonsson, M. Li, L. Mahrt, W. McGillis, A. Plueddemann, L. Shen, E. Skyllingstad, T. Stanton, P. Sullivan, J. Sun, J. Trowbridge, D. Vickers, S. Wang, Q. Wang, R. Weller, J. Wilkin, A. J. Williams, D. K. P. Yue, and C. Zappa. 2007. The Coupled Boundary Layers and Air-Sea Transfer Experiment in Low Winds, B. Am. Meteorol. Soc. , 88(3), 341-356.

Fabrice Ardhuin, Alastair D. Jenkins, Daniéle Hauser, Ad Reniers, and B. Chapron. 2005. Waves and Operational Oceanography: Toward a Coherent Description of the Upper Ocean, EOS, Transactions, 86(4), 37-44.

Grell, G. A., J. Dudhia, and D. R. Stauffer. 1995. A description of the fifth-generation Penn State/NCAR Mesoscale Model (MM5)Rep., National Center for Atmospheric Research, NCAR Tech. Note, NCAR/TN-398 + STR.

IOC, IHO, and BODC. 2003. Centenary Edition of the GEBCO Digital Atlas, published on CD-ROM on behalf of the Intergovernmental Oceanographic Commission and the International Hydrographic Organization as part of the General Bathymetric Chart of the OceansRep., British Oceanographic Data Centre, Liverpool, U.K.

James Edson, T. P., Scott Sandgathe, Linwood Vincent, Louis Goodman, Tom, J. H. Curtin, Marie Colton,, E. A. Steven Anderson, Stephen Burk, Shuyi Chen, Gennaro Crescenti, Eric D’Asaro,, M. D. Kenneth Davidson, James Doyle, David Farmer, Ann Gargett, Hans Graber, Dale, J. K. Haidvogel, Larry Mahrt, Michiko Martin, Julie McClean, Wade McGillis, Sean, J. M. McKenna, Peter Niiler, David Rogers, Eric Skyllingstad, Peter Sullivan,, and a. J. W. Robert Weller. 1999. Coupled Marine Boundary Layers and Air-Sea Interaction Initiative: Combining Process Studies, Simulations, and Numerical Models, edited, p. 140.

Kim, K. O., H. S. Lee, T. Yamashita, and B. H. Choi. 2008. Wave and storm surge simulations for Hurricane Katrina using coupled process based models, KSCE Journal of Civil Engineering, $12(1), 1-8$.

Kitaigorodskii, S., and J. Lumley. 1983. Wave-turbulence interactions in the upper ocean. part I: The energy balance of the interacting fields of surface wind waves and wind-induced three-dimensional turbulence, J. Phys. Oceanogr., 13(11), 1977-1987.

Lee, H. S., and T. Yamashita. 2009. Study on wind-wave-current interaction process in shallow water dynamics, Asian and Pacific Coasts 2009, 3, 65-72. 
Lee, H. S., T. Yamashita, and T. Komaguchi. 2008. Reanalysis of past major storms in West Kyusyu and study of wind-induced current in Ariake Sea, Journal of International Development and Cooperation, 14(2), 19-36.

Lee, H. S., T. Yamashita, T. Komaguchi, and T. Mishima. 2009. Reanalysis of Typhoon Meteorological Fields and Related Waves and Surges in the Seto Inland Sea, Journal of Japan Society of Civil Engineers, Ser. B2 (Coastal Engineering), 65(1), 441-445.

Longuet-Higgins, M. S., and R. W. Stewart. 1964. Radiation stresses in water waves; a physical discussion, with applications, Deep Sea Research and Oceanographic Abstracts, 11(4), 529-562.

Matsumoto, K., T. Takanezawa, and M. Ooe. 2000. Ocean Tide Models Developed by Assimilating TOPEX/POSEIDON Altimeter Data into Hydrodynamical Model: A Global Model and a Regional Model Around Japan, Journal of Oceanography, 56, 567-581.

Mellor, G. L. 2004. Users guide for a three-dimensional, primitive equation, numerical ocean modelRep., 53 pp, Prog. in Atmos. And Ocean. Sci.

Nairn, R. B., J.A. Roelvink, and H. N. Southgate. 1990. Transition zone width and implications for modeling surfzone hydrodynamics, Proc. 22nd International Conference on Coastal Engineering, 68-81.

Onogi, K., J. Tsutsui, H. Koide, M. Sakamoto, S. Kobayashi, H. Hatsushika, T. Matsumoto, N. Yamazaki, H. Kamahori, K. Takahashi, S. Kadokura, K. Wada, K. Kato, R. Oyama, T. Ose, N. Mannoji and R. Taira 2007. The JRA-25 Reanalysis, J. Meteor. Soc. Japan, 85, 369-432.

Polnikov, V. G., and P. Tkalich. 2006. Influence of the wind waves dissipation processes on dynamics in the water upper layer, Ocean Modeling, 11(1-2), 193-213.

Qiao, F., Y. Yuan, Y. Yang, Q. Zheng, C. Xia, and J. Ma. 2004. Wave-induced mixing in the upper ocean: Distribution and application to a global ocean circulation model, Geophysical Research Letters, 31(11), L11303.

Rogers, W. E., W. W. David, and A. H. Paul. 2003. Investigation of Wave Growth and Decay in the SWAN Model: Three Regional-Scale Applications, J. Phys. Oceanogr., 33(2), 366-389

Tkalich, P., and E. Chan. 2002. Breaking wind waves as a source of ambient noise, The Journal of the Acoustical Society of America, 112, 456. 